\title{
Combating Whole-Book Deterioration: The Rebinding \& Mass Deacidification Program at the Penn State University Libraries
}

\section{Suzanne Kellerman}

In this article, I describe the newly established preservation program at the Penn State University Libraries to deacidify en masse collections of older materials en route for commercial rebinding. This collection-based preservation strategy was designed to serve as a one-step-preparation approach for rebinding and for neutralizing the acid paper found in our heavily used, worm, and torn circulating collection. This strategy of combining commercial rebinding with deacidification has resulted in a timely and effective solution to preserve and stabilize collections for our users now while preventing future material deterioration. I will detail agreements and operational procedures developed among service vendors and the library, describe selection criteria, and document technical aspects to report this preservation action in bibliographic records.

S tion managers intently have watched the rapid evolution and development of mass deacidification technology as services, products, and vendors have come and gone over time (Boomgaarden 1995; Buchanan 1994; Cloonan 1990). The mass deacidification process, a preventive option to preserve acidic but-not-yet brittle and brittle materials in their original format, was once considered an unsafe and unreliable process. Today, this public perception and opinion has changed as researchers have shown in many scientific tests and studies that some processes indeed are effective in combating acidic paper degradation (Evaluation 1994). Additionally, when the Library of Congress conducted its own research and testing, and then awarded its first mass deacidification contract to Preservation Technologies, Inc. in 1996, many librarians began to reconsider mass deacidification seriously as a viable preservation tool (Harris 1998). At least one vendor reports that subsequent to these developments, contractual agreements between mass-deacidification vendors and libraries have been rising.

\section{BaCKGROUND}

Like many who were interested in the prospects of mass deacidification, librarians at the Penn State University Libraries (PSUL) began in 1991 to investigate vari-

L. SuZanne Kellerman (LSK@psulias.psu.edu) is preservation librarian, Penn State University Libraries, University Park. Manuscript received January 28, 1999; accepted for publication April 6, 1999. 
ous deacidification processes as a means to test claims that these techniques could safeguard paper-based materials printed on acidic paper (De Stefano 1994; Mass deacidification 1992; Sparks 1992). We conducted several pilot projects in 1991 and 1992 with the top three vendors of the time: FMC Lithium Corporation of America (Lithco), Akzo Chemical Inc., and Preservation Technologies, Inc. (PTI). Results of these independent tests were mixed. Our findings showed that some treatments adversely affected some types of books, papers, inks, and labels, while others displayed no negative effects. We were most encouraged by PTI's Bookkeeper process.

From 1992 to 1995, librarians worked with PTI to test enhanced treatment processes that PTI had developed and to establish in-house operational procedures and selection criteria policies. It soon became evident that books needed to be in good structural condition and fully intact to endure the treatment process. We discovered from these early tests that books in poor physical condition, e.g., volumes with loose boards or paper covers, broken spines, or detached pages, could not easily withstand the rigors of the treatment procedure and were further damaged by the mechanical agitation inherent in the process. In addition, books selected for the Bookkeeper treatment had to be durable and fully flexible to be attached to metal flanges splayed out or fanned open, which allowed each page and inner gutter margin to be exposed fully. This permitted a complete and even distribution of the neutralizing agent to all sections of the book. From these early tests, it became immediately apparent that books in poor physical condition would first require structural stabilization (first time binding or rebinding) to survive the treatment process successfully.

\section{The Initial Project}

In 1995, PSUL formally contracted its first mass deacidification project with PTI. We selected 163 volumes from among 2,000 volumes in the African American Studies Room for this initial project. Due to limited funding, we ap- plied certain selection criteria to identify the volumes that were the best candidates for the process. We assessed books individually to determine structural integrity and level of paper acidity. Only structurally sound books printed on acidic paper made the first cut as potential deacidification candidates. We further narrowed this subcollection based on circulation use patterns, giving a priority to the most heavily used items, or those with a circulation count of 8 or more. Books meeting all of the above criteria had to be physically available, i.e., on the shelf at the time of the assessment.

We preselected materials over a two-month period and sent them to PTI in June 1995. A month later, treated books were returned to the library, where we conducted physical inspection and random $\mathrm{pH}$ testing (using a $\mathrm{pH}$ testing pen) on them. Results of the testing showed that $85 \%$ of the deacidified materials ( 138 books) had been treated successfully with no adverse effects to papers, inks, or labels. Of the remaining $15 \%$ ( 25 books), the major problem was that of partial treatment (nonuniformity), especially in the inner margins of some volumes (Evaluation 1994).

The success of this first, small-scale mass deacidification project encouraged us to plan an ongoing, larger scale mass deacidification program for PSUL. We continued to work with PTI to resolve the "fish-eye" problem of partial treatment found in some materials and focused our attention on formulating a plan to implement this new preservation program.

Based on our experience working with PTI's Bookkeeper process, we learned several important factors that influenced the success or failure of using this treatment process as a viable preservation option. First, books had to be structurally sound to withstand the rigors of the process. Second, not all paper types absorbed the neutralizing agent equally well, e.g., clay-coated paper. Third, tracking each item sent for treatment was essential in order to keep library patrons informed of material availability. Fourth, internally, we recognized the need to implement the use of the USMARC 583 field to report 
this preservation action in our local bibliographic records for our users. Fifth, we needed to identify an ongoing funding source to support the program. Finally, we needed to develop selection criteria to determine which library collections or portions of collections were best suited for mass deacidification.

\section{Selection Criteria for Mass DEACIDIFICATION}

At PSUL, we initially planned to target portions of our older collections and some new acquisitions for mass deacidification treatment based on the findings of a study we conducted in 1992. During this 1992 study, we surveyed and tested 5,362 new books with imprint dates of 1990, 1991, and 1992, received through our approval plan programs, to determine the percentage of books printed on acidic paper versus those printed on alkaline paper. Results of the study revealed that of all books surveyed (hardbacks and paperbacks from 33 countries worldwide), $86 \%$ were printed on alkaline paper; only $14 \%$ were printed on acidic paper. Of the books published in the U.S., $91 \%$ were printed on acid-free paper. Although impressive, these figures were not all that surprising in light of the 1989-90 call for commercial publishers to use permanent paper and for paper mills to produce acid-free paper. Production of alkaline paper was becoming the norm in paper production in North America (Preserving Knowledge 1990). Books published in third-world regions were the exception, e.g., books published in India and Africa were highly acidic. With only one exception, all books from these two countries were printed on acidic paper.

Based on our study, it became apparent that a high percentage of newly acquired materials, printed on alkaline paper, were not at risk as previously thought. Our older collections residing in the stacks were more likely to have been printed on acidic paper, were more subject to deterioration, and therefore were at far greater risk. As noted above, new materials published in some third-world countries were exceptions to this rule.

In 1997, five years after our initial collection survey, we conducted two additional studies to determine whether any changes had occurred in the publishing industry that might affect our earlier decision about which collections would benefit most from deacidification treatment. We surveyed newly acquired materials and older circulated materials sent to the Preservation Collections Care Unit for conservation treatment (repair, rebinding).

We performed a pH test on 447 newly acquired books (both paperbacks and publisher bound materials) to determine paper acidity. Domestic and non-U.S. published materials received through firm orders, approval plans, or monograph and serial acquisitions processes were represented among these titles. Of the $447 \mathrm{vol}$ umes tested, less than $1 \%(.06 \%)$ were found to be printed on acidic paper.

Later that year, over a two-month period in the fall semester, we conducted a $\mathrm{pH}$ test on 156 recently circulated books returned from patron use. As books were returned to Lending Services, staff identified materials in poor physical condition and sent them to the Preservation Collections Care Unit for repair. Condition of these materials varied and included loose or missing covers, torn or loose pages, broken spines or headcaps, and missing pages. These 156 volumes represented publications from both the U.S. (96\%) and abroad $(4 \%)$. Of the 156 volumes surveyed, we found that $82 \%$ were printed on acidic paper; $18 \%$ were printed on alkaline paper.

Based on the survey results from these two tests, it was apparent that the older materials were most at risk by evidence of their poor worn and torn physical condition and their acid content. We then created a one-step-preparation approach for combining rebinding with mass deacidification as a whole-book strategy. Previously, other libraries using mass deacidification had used similar selection criteria for identifying suitable candidates, but varied in the sequence of the treatment process (De Stefano 1994).

In April 1998, we held a meeting with library selectors to share these survey test results and to discuss the combined re- 
binding and mass deacidification program as a treatment option for acidic collections. Selectors at the meeting agreed that the combined process was a viable preventive preservation option and that the following materials should be considered for treatment, listed in order of priority:

1. Circulating materials needing conservation attention, as identified by Lending Service staff (from the University Park main campus location only)

2. Selected discreet collections of distinction identified by library selectors

3. Selected individual titles identified by library selectors

Once we established these selection priorities, librarians in the Preservation Department accelerated their efforts to finalize planning of operational procedures for a combined rebinding and mass deacidification program for PSUL. In addition, a newly established preservation endowment secured financing to support this new preservation program. We held numerous collaborative meetings with the service vendors involved (both a commercial binder and a mass deacidification service provider) to establish service agreements. We also held meetings with staff from various library departments (Lending Services, Stack Maintenance, Cataloging and the Business Office) to establish internal workflow procedures for handling, tracking, shipping, and billing.

PSUL established the agreements and operational procedures presented in this paper in collaboration with its vendors. We have outlined them here as an example of how similar projects might be structured. The first section describes mutually agreed-upon library requirements and vendor specifications for the process. The following section documents the internal operating procedures established for sending worn and torn circulating materials for rebinding and mass deacidification treatments.

\section{LIBRARY REQUIREMENTS AND \\ VENDOR SPECIFICATIONS}

Having committed to this unique one-step preparation process as an acceptable pres- ervation option, PSUL established basic preservation requirements for the rebinding and mass deacidification treatment processes. One of these requirements was that all materials be rebound or first time bound using C-Grade bookcloth following the standards for commercial binding set forth in Parisi and Merrill-Oldham (1986). We also determined that the acceptable range of $\mathrm{pH}$ levels for treated materials would be 6.5 to 10.4 with a minimum required alkaline reserve level of $1 \%$. Both vendors had to notify the library if materials could not be bound or mass deacidified for any reason. The binding vendor had to supply a shipping schedule. The deacidification vendor had to supply surrogate $\mathrm{pH}$ testing paper reports for each shipment and also track all incoming items by call number or barcode for easy identification.

In addition to our library requirements, we profiled vendor-specified stipulations to ensure efficient throughput and turnaround time. Working collaboratively, the library staff, binder, and deacidification vendor defined additional program specifications. The library staff agreed that each shipment would have a minimum number of 30 volumes and that items would not exceed $12^{\prime \prime} \times 9^{\prime \prime} \times 2.5^{\prime \prime}$ in size nor weigh less than 2.8 pounds. The binder required the library to send materials two weeks prior to their shipment to the mass deacidification vendor to ensure sufficient time for rebinding. The binder agreed to rebind and ship bound books to and from the deacidification vendor's facility, and then transport treated books back to the library within a total turnaround time of 6 to 8 weeks.

It was also agreed that the binder would arrange the shipment from smallest to largest to facilitate processing and handling by the mass deacidification vendor. In turn, the deacidification vendor would return the books in the order they were received. Other program requirements called for the binder to contact the library if any materials were found not suitable for mass deacidification (e.g., volumes that were brittle, oversized, or that weighed more than 2.8 pounds), and for the deacidification vendor to supply 
vendor identification labels stamped with the treatment date for in-house application to each treated book. Finally, each vendor had to submit separate invoices for products and services rendered.

Once an agreement with external vendors was reached, PSUL then initiated internal procedures to implement the process.

\section{INTERNAL LIBRARY OPERATIONS}

Based on the Preservation Collections Care Unit staff's current responsibilities of assessing materials for preservation treatment, it seemed logical for staff in this unit to assume responsibility for managing the mass deacidification program. While many of the assessment activities were similar to ones already in place, we needed to add some new procedures. These included evaluating and selecting materials based on newly established criteria, bibliographic processing, physical preparation, and online tracking of materials sent for rebinding or first-time binding and mass deacidification.

Following the established selection criteria, the staff conducted item-by-item preselection assessment to identify candidates for mass deacidification treatment. Physical and use-related factors used to identify candidates for mass deacidification treatment included:

- Any volume (bound or not bound) printed on acidic wood-pulp paper

- Paperbacks or hardbacks in poor condition and needing to be rebound prior to mass deacidification treatment

- Items limited in size up to and including $12^{\prime \prime} \times 9^{\prime \prime} \times 2.5^{\prime \prime}$ (vendor requirement)

- Volumes weighing 2.8 pounds or less (vendor requirement), and

- Items with a circulation count of 5 or more

Based on previous experience, internal decisions, and discussions with vendors, we identified the following materials and format types as not being appropriate for mass deacidification treatment:

- Text paper that is alkaline

- Manuscript materials

- Items published on glossy clay-coated paper

- Leather covers with red rot
- Materials with plasticized covers

- Brittle text paper (if fails at two double folds)

- Materials with accompanying pocket parts

- Titles that are not permanently retained

- Titles found on microfilm or microfiche

To determine whether published texts were printed on acidic paper, we performed a $\mathrm{pH}$ test. Using a $\mathrm{pH}$ chlorophenol red pen, we drew a small line on the tail of each volume closest to the spine. The chlorophenol red indicator solution turned purple if the $\mathrm{pH}$ of the paper was 6.8 or above, indicating that the paper was alkaline. A clear or yellow color marking indicated the paper was acidic and the volume was a candidate for mass deacidification. We chose this method for testing $\mathrm{pH}$ solely for its ease of use and process efficiency in determining a general acidity reading.

\section{Bibliographic Processing}

Once we assessed the materials, tested them for paper acidity, and sorted them for mass deacidification treatment, staff in Collections Care updated the bibliographic cataloging records for each title or volume selected. They updated item records and charged out each item to a single department charge, coded MASS. The automatic mnemonic display code MASS was established to appear in the online catalog to alert users and library staff that the item had been sent for deacidification, and was temporarily unavailable (see figure 1). This mnemonic code displays whenever the status of an item is requested through an "item inquiry" command. Or, if a patron checks the status of an item, the display will read "1 Dept. Charge," also indicating the item is unavailable for use (see figure 2).

While the USMARC 583 standard has yet to be officially approved as the bibliographic field to record information about processing and preservation action taken on bibliographic materials, we adopted ALA recommended guidelines and terminology for using notes field 583 for this 
*Item Inquiry *

Item Number: 33748184

The death of the automobile Jerome, John.

Item: 33748184

Cal1 No: HE5623. J47

Last Circ: 01/18/1999 03:01 PM

Circ count: 2

Pattee

Dept: MASS

* ITEM*

01/18/1999 05:54 PM

Figure 1. Item Inquiry Display Showing an Item That has Been Department Charged to MASS and is Temporarily Unavailable.

purpose. Vendor-specific information (name and address), type of treatment performed (liquid deacidification, rebound, rehoused, etc.), and date of treatment are entered in the 583 notes field (see figure 3). These preservation data only appear in local cataloging records and are not keyed into the records in the bibliographic utilities, nor are they mounted by tape loading. The local definition used for notes field 583 is:

$583 \$$ a Description of the action taken $\$ \mathrm{c}$ date of action $\$ \mathrm{i}$ method of action $\$ \mathrm{x}$ additional treatment information - deacidification treatment used $\$ \mathrm{j}$ address of vendor $\$ \mathrm{k}$ vendor name $\$ \mathrm{z}$ additional treatment information

In addition to using USMARC 583 fields in each bibliographic record, a 598 field was added to indicate the preservation action taken for a specific volume or specific copy. For example, if only one copy of a title with multiple copy locations

The death of the automobile, the fatal effect of the Golden Era, 1955-1970. / Jerome, John. [1st ed.]. [1972].

HE5623.J47

-Central Pattee Level 4

(Location in stacks)Blue-

1 Dept. Charge

Figure 2. Online Catalog Status Display Showing an Item that Has Been Department Charged. was treated, a 598 note field was added to identify the specific copy that has been treated (see figure 3). The 598 field is defined as a local free text note used for reporting internal processing. The local definition of field 598 is:

598 \$a Processing instructions

Other examples of reporting when a specific volume was deacidified include:

- 598 Engineering copy deacidified

- 598 Physical Sciences v. 2 deacidified

- 598 [barcode \#] deacidified

- 598 Stacks v. 1 deacidified

\section{Materials Preparation}

After we completed the online bibliographic updating, we generated a two-part printout of the bibliographic record (see figure 4). We detailed binding and spine stamping instructions as well as notification of mass deacidification treatment on the printout. We inserted a portion of the printout sheet into the volume being sent for treatment; we placed the extra sheet in a packet. We filed each packet alphabetically by title and then by shipping date.

We took and recorded separate statistics for volumes prepared for rebinding and mass deacidification. We then assembled and packed the books into a sturdy commercial binder shipping box marked "MASS DEACIDIFICATION," and sent the box to the commercial binding vendor.

\section{Post-Treatment Processing}

Once items were returned to the library, the Collections Care staff reviewed and inspected each volume for accuracy in rebinding (letter stamping, etc.) and for paper acidity. Staff used paperwork to compare requested binding type and spine stamping with the book in hand. Staff members also visually inspected each book for the proper placement of the infinity symbol at the top of the spine to identify that the book had received mass deacidification treatment. Adding this mark to the outside of each treated book allowed for a quick visual display of which books have and have not been treated. A mass deacidification vendor identification label on the verso of the title page 


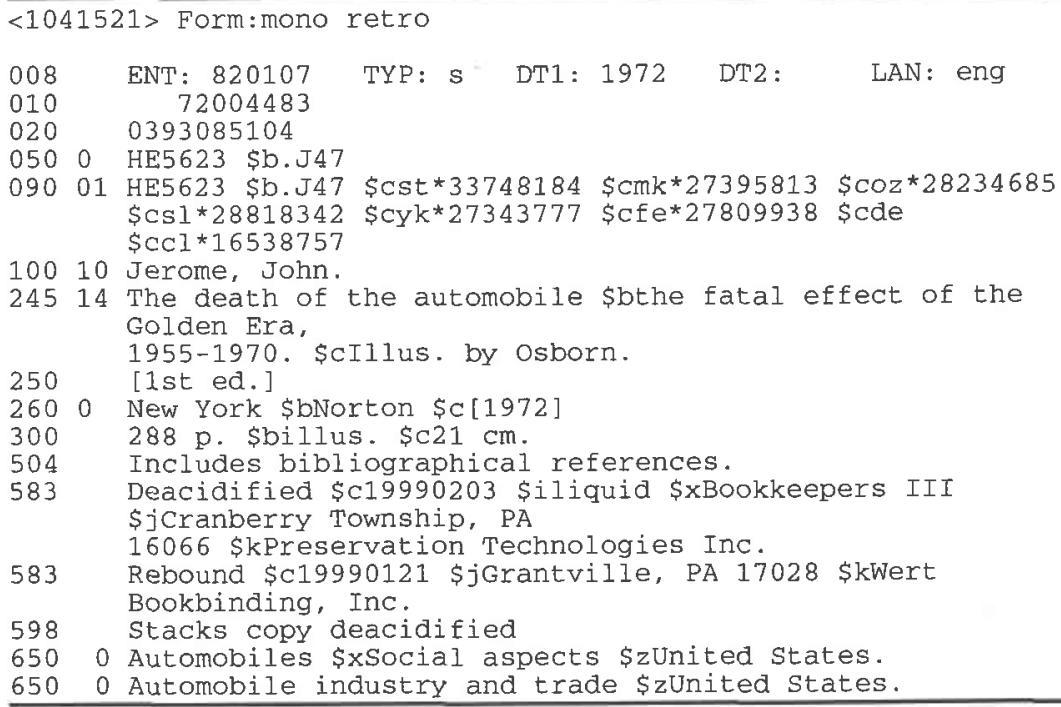

Figure 3. Online Record Showing Use of Multiple 583 Fields and the 598 Field to Report Preservation Action Taken.

provided treatment information for library staff and patrons. The staff then conducted a random $\mathrm{pH}$ test to confirm treatment results.

After completing the physical and technical inspections, staff then added a giftplate to the book's inside front cover to denote the funding source used for the book's preservation. Staff then updated each item record and discharged the item, making the item available for use in the online catalog. Books were then ready to be reshelved and were returned to circulation.

\section{Conclusion}

As of this writing, we have prepared and shipped three 100 -volume shipments for rebinding and mass deacidification and has received two return shipments. Turnaround time for each shipment was seven weeks. From all indications, the vendor and library specifications and requirements outlined have accurately described the process. Neither the vendors nor the library staff encountered problems in preparing or inspecting returned materials, so no changes in specifications

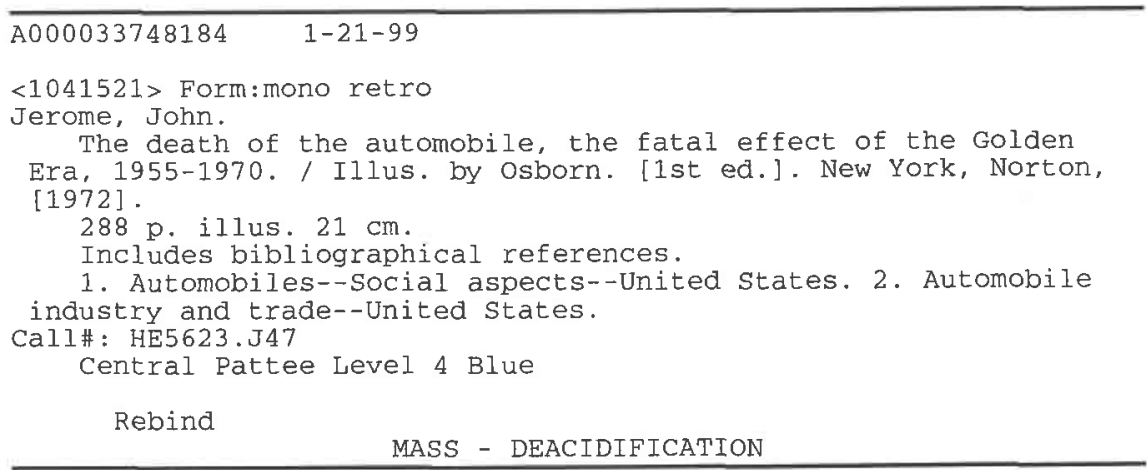

Figure 4. Sample Printout with Vendor Instructions. 
or procedure were required. Although some fine-tuning of the procedures might be necessary as this program matures, for now it appears this new preservation strategy could become our most efficient process for stabilizing older collections using a one-step preparation approach.

\section{WORKS CITED}

Boomgaarden, Wesley L. 1995. Mass Deacidification. In Managing preservation a guidebook: A cooperative publication of the State Library of Ohio and the Ohio Preservation Council. Columbus, Ohio: State Library of Ohio and the Ohio Preservation Council.

Buchanan, Sally A. 1994. Mass deacidification. Wilson library bulletin 69, no. 4: 58-59.

Cloonan, Michele Valerie. 1990. Mass deacidification in the 1990s. Rare book and manuscript librarianship 5, no, 2: 95-103.

Cunha, George M. 1989. Mass deacidification for libraries: 1989 update. Library technology reports 25 (January/February): 5-81.

De Stefano, Paula. 1994. New York State combines mass deacidification with rebinding. Conservation administration news no. 58-59 (July/October): 22-24.

Evaluation of the Bookkeeper mass deacidification process: Technical Evaluation Team report for the Preservation Directorate, Library of Congress. 1994. Pittsburgh.

Harris, Kenneth E. 1998. Library of Congress mass deacidification program. New library scene 17, no. 3 (September): 8-9.
Mass deacidification: a report to the library directors, Committee on Institutional Cooperation (CIC), CIC Task Force on Mass Deacidification. 1992. Champaign, Ill.: Committee on Institutional Cooperation.

Parisi, Paul and Jan Merrill-Oldham, eds. 1986. Library Binding Institute standard for library binding, $8^{\text {th }}$ ed. Rochester, N.Y.: The Institute.

Porck, Henk J. 1996. Mass deacidification: An update on possibilities and limitations. Amsterdam: European Commission on Preservation and Access; Washington, D.C.: Commission on Preservation and Access.

Preserving knowledge: The case for alkaline paper. 1990. Rev. ed. Washington, D.C.: Association for Research Libraries.

Sparks, Peter G., ed. 1992. Roundtable on mass deacidification: Report on a meeting held September 12-13, 1991 in Andover, Mass. Washington, D.C.: Association of Research Libraries.

Sparks, Peter G. 1990. Technical considerations in choosing mass deacidification processes. Washington, D.C.: Commission on Preservation and Access.

Swartzburg, Susan G. 1995. Paper: problems and solutions. Chapter 8 in Preserving library materials: A manual, $2 \mathrm{~d}$ ed. Metucher, N.J.: Scarecrow Press, Inc.

Turko, Karen. 1990. Mass deacidification systems: Planning and managerial decision making. Washington, D.C.: Association of Research Libraries.

\section{INDEX TO ADVERTISERS}

Library Technologies

Archival Products

Haworth Press

OCLC
$2 d$ cover

169

3rd cover

4th cover 